\title{
Participación política de pecheros mirobrigenses en el feudalismo tardío: del usufructo de la retórica formal del discurso a la vertebración de una cultura política propia
}

\author{
Political Involvement of Taxpayers in Ciudad Rodrigo during \\ Late Feudalism: From the Use of Formal Rhetoric in Discourse to \\ the Creation of a Specific Political Culture
}

\author{
Silvina Andrea MondRAgóN \\ Universidad de Buenos Aires. República Argentina \\ silvinamondragon@yahoo.com
}

\begin{abstract}
RESUMEN
A partir de documentación municipal mirobrigense tardomedieval, se rastrean mecanismos políticos de los pecheros, tanto de resistencia como de acción concreta, articulados en un marco de centralización de los poderes regios y de agudización del proceso de diferenciación social de las comunidades campesinas. Es en este contexto histórico particular que se vertebra una "cultura política" propia de pecheros enriquecidos, posible de ser rastreada en la documentación a partir de determinadas estrategias, como la utilización de la retórica formal del discurso político en que se expresaba la oposición privilegiados/no privilegiados para lograr la consecución final de sus intereses.
\end{abstract}

Palabras clave: Poder político tardomedieval castellano, Diferenciación social del campesinado, Concejos de realengo.

\begin{abstract}
Based on late medieval municipal records from Ciudad Rodrigo, it is possible to identify political mechanisms used by taxpayers, both of resistance and concrete action in the context of the centralization of royal power and a process of progressive socio-economic differentiation of the peasant communities. It is in this historical context that a "political culture" was created by the richest taxpayers. This can be traced in the records through certain strategies such as the use of political discourse that expressed a dichotomy between 'privileged' and 'non-privileged' to achieve the results they were aiming for.
\end{abstract}

Key words: Late Medieval Castilian Political Power, Social Differentiation of the Peasantry, Realengo Town Councils.

Sumario: 1. Introducción. 2. Identidad y discurso político de pecheros en Ciudad Rodrigo a mediados del siglo XV. 3. El declive de lo que fue: la creciente debilidad de la participación política colectiva de pecheros mirobrigenses en la segunda mitad del siglo XV. 4. Conclusiones. 


\section{INTRODUCCIÓN}

Tanto para las corrientes interpretativas que en los años ' 80 del pasado siglo, sentaron los puntos básicos para lograr una taxonomía precisa del sector pechero ${ }^{1}$ castellano tardomedieval ${ }^{2}$, como para las líneas más novedosas que hoy en día buscan desentrañar su cosmogonía, la participación política del "común" es un tópico ineludible $^{3}$. El registro historiográfico actual está dominado por aquellos trabajos que hacen hincapié en la importancia de las manifestaciones menos tangibles de la cultura política como el mundo de las representaciones mentales ${ }^{4}$. Así, en un artículo reciente, el historiador español Monsalvo Antón ${ }^{5}$ se preguntaba si los miembros del común concejil castellano habían sido capaces de generar un discurso social y político autónomo a fines de la Edad Media.

La pregunta no era capciosa, se erguía frente a una tradición interpretativa que durante mucho tiempo había sostenido la nulidad del interés por reconstruir el perfil político del sector tributario en algunos casos, en tanto que en otros se les negaba directamente la capacidad de intervención política en instancias de poder formales e informales, al pensarlos como sujetos pasivos sobre los que recaían intereses de grupos oligárquicos, que condicionaban las lógicas de reproducción social y cultural del sector ${ }^{6}$.

Estas posturas se derivaban de interpretaciones historiográficas que recuperaban de manera formal los reclamos de los pecheros sin considerar la mediación que im-

${ }^{1}$ La condición de pechero estaba básicamente definida por la obligación del pago de pechos, derivaba de la condición jurídica de no privilegiados.

${ }^{2}$ Algunos ejemplos de estudios ya clásicos: Asenjo GonzÁlez, M: "Labradores ricos: nacimiento de una oligarquía rural en la Segovia del siglo XV", En la España Medieval № 4, 1984; Monsalvo Antón, J. M: El sistema político concejil. El ejemplo del señorío medieval de Alba de Tormes y su concejo de villa y tierra, Salamanca, 1988; Diago Hernando, M.: "El 'común de los pecheros' de Soria en el siglo XV y primera mitad del XVI", Hispania, 174, L/1, 1990; Del Val Valdivieso, M. I: "Ascenso social y lucha por el poder en las ciudades castellanas del siglo XV", En la España medieval, 17, 1994.

${ }^{3}$ Obviamente, la polarización del campesinado no impide su consideración como clase, determinada por la obligación de tributar y por la exclusión del privilegio. Podían estar diferenciados por una multiplicidad de variables que insidían en la forma en que se reproducía el sector: por ejemplo por cuestiones económicas como la participación de algunos campesinos enriquecidos en la gestión de la renta o por cuestiones político-culturales perfiladas a partir del lugar de residencia: la vida en el concejo cabecera o en la Tierra de éste daba lógicamente resultados diferentes en cuanto al grado de participación o incidencia política del sector en sus respectivos concejos.

${ }^{4}$ Estas perspectivas se pueden encontrar en dos trabajos de síntesis recientes: AA. VV: Construir la identidad en la Edad Media. Poder y Memoria en la Castilla de los siglos VII a XV, Cuenca, 2010 y Fernandez de Larrea, J. y Diaz de Durana, J: Memoria e Historia. Utilización politica en la Corona de Castilla al final de la Edad Media, Madrid, 2010. Por otra parte, autores como José Antonio Jara Fuente, han comenzado a estudiar el plano de la construcción de las identidades políticas desde una perspectiva que prima el análisis culturalista. Un ejemplo en JARA Fuente, J. A: "Percepción de sí, percepción del otro: la construcción de identidades políticas urbanas en Castilla (el concejo de Cuenca en el siglo XV", Anuario de Estudios medievales, 40/1, 2010.

${ }^{5}$ Monsalvo Antón, J. M: "Ideario sociopolítico y valores estamentales de los pecheros abulenses y salmantinos (ss. XIII - XV), Hispania, LXXI (238), 2011, p. 326.

${ }^{6}$ Freedman, P: "La resistencia campesina y la historiografía en la Europa medieval", Edad Media Revista de Historia, Vol. 3, 2000, pp. 20-38. 
plicaba su formulación por parte de los representantes aldeanos ${ }^{7}$; en buena medida producto lógico de la ausencia de voces tributarias directas que se inferían por la acción de interpósita persona que hacía constar los reclamos que estos lideraban o los pleitos en los que generalmente se enfrentaban a las oligarquías urbanas y que tenían llegada a instancias de poder central ${ }^{8}$. Esta falta de evidencia directa de las representaciones políticas de pecheros dificultó la definición de un perfil acabado del sector en tanto no se les reconocían grados de autonomía política o de conciencia, ya que bajo estos supuestos analíticos era imposible armar el rompecabezas de su participación en instancias formales de poder ${ }^{9}$. Las veces que aparecía evidencia directa en la documentación se evaluaba como nodos aislados, no pasibles de facilitar una síntesis de las conductas políticas del sector.

Para lograr una interpretación de conjunto de la actividad política de pecheros, se debe hacer hincapié en conocer los mecanismos por los que se reproducía el mundo mental de los sectores subalternos (desde lo material y simbólico) para conocer la forma en que la dinámica reproductora de sus condiciones básicas de existencia condicionaba la estructuración de sus mecanismos políticos ${ }^{10}$.

A partir de estas perspectivas analíticas y de documentación municipal del concejo mirobrigense y en especial de dos memoriales de agravios presentados por pecheros en 1419 y $1455^{11}$ respectivamente, este trabajo busca analizar la factibilidad de reconstruir los perfiles de una cultura y una identidad política desarrollada y perfilada

7 Entendemos que esta mediación es la que daba por resultado una retórica formal del discurso político pechero, que básicamente los presentaba como no privilegiados con el fin de enfrentar la defensa de lo que les interesaba desde un lugar de debilidad frente al cual el monarca no podía ejercer un arbitrio de su voluntad equitativo ya que desde la mera enunciación política por la cual se expresaban, las oligarquías aparecían como los agentes expoliadores del sector. Esta retórica solía aparecer expresada como juego de opuestos: ilegalidad/legalidad; clientelismo/vecindad; agresores violentos /víctimas; inmoralidad/moralidad; individualismo/comunalismo, mengua de justicia/mentalidad justiciera; en Monsalvo Antón, J. M: "Usurpaciones de comunales: conflicto social y disputa legal en Ávila y su Tierra durante la Baja Edad Media", Historia Agraria n² 24, 2001, p. 106.

8 Aparece bajo fórmulas del tipo: “...sepades que por parte de los pueblos e tierra desa dicha cibdad nos fue fecha relación por su petición, que en nuestro concejo fue presentada, diziendo que en esa dicha cibdat se ha tratado e tracta ante vós ciertos pleitos que son entre los dichos pueblos e tierra e ciertos concejos e personas particulares desa dicha cibdad, e que a cabsa que non los determinárades nin sentenciárades, por parte de los dichos pueblos fue ganada una nuestra carta para que luego los sentenciárades..." Garcia Perez, J. J: Documentación Medieval Abulense en el Registro General del Sello, Vol. XVI, Ávila, 1998, doc. no 42, p. 79.

9 Sin embargo Monsalvo Antón ha sostenido que "hay una identidad mínima: su condición de no privilegiados, de contribuyentes. En ella se sustentaba una toma de conciencia elemental- sin ella no hay acción política- sobre su situación, percibida explícitamente de manera inmediata y seguramente concebida bajo esquemas de estratificación social. Era además una toma de conciencia que había surgido pronto, mucho antes de la implantación del Regimiento", en Monsalvo Antón, J. M: "La participación política de los pecheros en los municipios castellanos de la baja Edad Media. Aspectos organizativos", op. cit., p. 40.

10 Para una comprensión de los aspectos de forma integral insidían en los mecasnismos de reproducción de las comunidades y sobre todo de sus elites, ver FurIO, A: "Las elites rurales en la Europa Medieval y Moderna. Una aproximación de conjunto" en Rodriguez, A (Ed): El lugar del campesino. En torno a la obra de Reyna Pastor, Valencia, 2007.

${ }^{11}$ Este documento en particular aparece como apéndice documental del artículo de Monsalvo Antón, J. M: "Aspectos de las culturas políticas de los caballeros y los pecheros en Salamanca y Ciudad 
por tributarios mirobrigenses, evidente en el discurso político del siglo XV pero producto de siglos de tradición campesina desplegada en espacios físicos condicionados por el entramado social, económico, político e ideológico que la materialidad del feudalismo imponía.

La cuestión nodal sigue siendo rehabilitar al campesinado como sujeto político, de lo que se desprenderá lógicamente la reconstrucción de un sistema de representaciones mentales desde el que intervinieron frente a los demás actores. Es por ello que se entiende que en cada evidencia, por pequeña que sea, de voces tributarias directas se soslayan tradiciones culturales que compusieron formas de pensar y entender la realidad, construidas en buena medida de forma colectiva como sumatoria de experiencias que desde lo individual trascendieron para conformar formas conjuntas de entender la realidad y que eran indicativas del grado en que los pecheros asumían determinados fenómenos de la esfera pública y de su capacidad de integrarlos en una visión del pasado concreta que diera sentido a su presente.

De allí que haya que ponderar en el análisis la incidencia total que los mecanismos de reproducción social y económica de cada concejo ${ }^{12}$, en definitiva la dinámica de la base material que condicionaba sus rutinas cotidianas, tuvieron sobre la articulación de lógicas políticas propias y/o autónomas del sector ${ }^{13}$.

\section{IDENTIDAD Y DISCURSO POLÍTICO DE PECHEROS EN CIUDAD RO- DRIGO A MEDIADOS DEL SIGLO XV}

Junto con Ávila y Salamanca, Ciudad Rodrigo fue uno de los principales concejos de villa y tierra del suroeste castellano durante la Edad Media. ${ }^{14}$ Sin embargo, condicionantes de tipo geopolítico hicieron que no pueda ser homologado a las demás tierras realengas, más que en lo concerniente a su condición de propiedad eminente del monarca: su situación geográfica de concejo de frontera con el reino de Portu-

Rodrigo a mediados del siglo XV. Violencias rurales y debates sobre el poder en los concejos", Anexes des CLCHM, Vol. 16, 2004, en adelante: "Memorial".

${ }^{12}$ Lejos de componer un espacio homogéneo, los concejos tanto villanos como rurales, constituyeron escenarios complejos producto de su propia dinámica constitutiva, por lo que no podemos pretender encontrar idearios políticos unívocos entre todos ellos o entre estos y los términos segregados, ahora convertidos en señoríos de particulares. Así como tampoco es esperable encontrar en la documentación discursos políticos lógicamente preconcebidos o articulados a priori en torno a algún tema concreto que exceda lo que directamente afecta y por tanto, interesa a los tributarios. Esta dinámica compleja y original, estaba incluso marcada por la estructura de la base productiva que lejos de dividirse tajantemente entre pecheros labradores y caballeros dedicados a la ganadería, en realidad, se caracterizaba por la convivencia de ambas esferas productivas en pequeña escala entre los dos sectores sociales.

${ }^{13}$ Corina Luchía sostiene que "las cualidades del trabajo agrario con la ineludible regulación de usos acorde al ciclo agrícola y a las diferencias de suelos generan una dimensión comunitaria que no es solo producto de la preexistencia de solidaridades aldeanas, sino de los propios fundamentos de las condiciones de producción campesinas bajo el feudalismo", LuchIA, C: "Categorías económicas, prácticas sociales y percepciones en el mundo rural castellano. Siglos XIV - XV", en Anales de Historia Antigua, Medieval y Moderna, $\mathrm{N}^{\circ} 44$, en prensa.

${ }^{14}$ Una síntesis de la historia medieval mirobrigense en Bernal Estevez, A: Ciudad Rodrigo en la Edad Media, Salamanca, 1981. 
gal, involucrado en el siglo XIV en la guerra de sucesión entre Pedro I y Enrique de Trastámara, hizo que se convirtiera en escenario y campo de más de una batalla. Esta circunstancia, sin embargo, provocó que se desplegaran en el largo plazo procesos de acumulación material que redundaron en una marcada fragmentación social del "común" concejil ya que como recompensa por los combates que se libraban en su término, los vecinos mirobrigenses consiguieron desde temprano importantes ventajas y privilegios, que entendemos, contribuyeron a consolidar una elite de tributarios rurales sólida desde lo político, con capacidad de acción autárquica que se fortalecía en la medida en que los concejos rurales escapaban cada vez más del control jurídico y político del concejo de cabecera ${ }^{15}$.

Uno de los objetivos de este trabajo consiste en rastrear la función que los pecheros atribuían a su participación política a través de los dispositivos institucionales concejiles, lo que a su vez modelaba la construcción política e identitaria del sector.

En el complejo entramado de representaciones político-ideológicas de la Baja Edad Media castellana, los miembros de las oligarquías urbanas habían naturalizado prerrogativas sociopolíticas y económicas en el contexto de su pertenencia al estamento privilegiado por lo que no estaba sujeto a discusión el hecho que les correspondiera el control del aparato de gobierno concejil. Esto descansaba básicamente en el peso de la tradición y la costumbre que desde tiempos inmemoriales daban sentido a un criterio de superioridad social y política que no era amenazado en su razón de ser por la defensa de intereses propios que otros sectores sociales pudieran llevar a cabo al hacer participar de los dispositivos políticos que tenía el realengo. Veamos un ejemplo concreto de lo que comentamos en las diecinueve denuncias presentadas en 1455 por el procurador pechero ${ }^{16}$ ante los regidores mirobrigenses.

La primera de ellas alude a la prohibición que pesaba sobre el sector de participar con voz y voto en las sesiones del concejo. La respuesta que dan los regidores se ampara en la tradición y por ende en la defensa de un sistema político que excluye la participación política de las mayorías en los planos formales del gobierno local:

“...A esto respondemos que nunca el sesmero desta cibdad tobo voz nin preheminencia para poder estar en concejo contra voluntad de la justicia e regidores de la dicha cibdat ... crehemos que, sy voz el dicho sesmero toviese e en concejo entrase syenple quando a él proguiese seguir, serýa grand daño a la dicha cibdad e su tierra, ca conmo el dicho oficio de sesmeria consista comúnmente. Segund por experiencia es demostrado, en presonas de pequeño estado e abtoridat que han de dar a muchos cuenta (...) Aunque posyble sería quel dicho Luys Martínez fuese tal que guardaría lo

${ }^{15}$ Este proceso de distención del control hegemónico del concejo cabecera sobre su tierra era producto en buena medida de la política de otorgamiento de señoríos a particulares que se segregaban del realengo y que fue característica de los primeros trastámaras. Sobre la noción de realengo transferido Monsalvo ANTÓN, J. M: "Centralización monárquica castellana y territorios concejiles (algunas hipótesis a partir de las ciudades medievales de la región castellana leonesa", en Anales de la Universidad de Alicante $\mathrm{N}^{\circ} 13,2000 / 2002$.

${ }^{16}$ El procurador era un representante del sector que provenía de la elite pechera, por lo que es de suponer que respondía a los intereses de esta y no a los del colectivo; al respecto AstaRITA, C: "Procuradores pecheros", Del feudalismo al capitalismo. Cambio social y político en Castilla y Europa Occidental, 1250-1520, Valencia, 2005. 
que le fuese encomendado, pero sería abrir puerta a otros que después fuesedn que non lo guardarían, lo qual sería ynjusto, e pues que nunca fue non se debe agora fazer..."17

Es evidente que los regidores definían desde su pertenencia al estamento privilegiado un lugar de participación política casi exclusivo, que infravaloraba los destinados a los pecheros y sus representantes. El oficio pechero era así una expresión mínima, por lo que no era depositario de algún grado de autoridad, por mínima que esta pudiera resultar en estos espacios.

Asimismo consideraban que los representantes pecheros estaban intrínsecamente incapacitados para "guardar" las resoluciones del concejo, dando por sentado que había algo que guardar del resto, ya que solo una parte del tejido social calificaba para enterarse de lo que allí se decidía, a pesar que era claro que el corolario de la toma de decisiones afectaba a todos.

Otro dato interesante que revela la cosmogonía de los regidores es que negaban al colectivo pechero la pericia necesaria como para participar con voz y voto del gobierno concejil, aunque contemplaban eventualmente la posibilidad de otorgar la confianza necesaria a su representante, Luys Martínez (el representante del sexmero por la villa), en calidad individual y como anomalía, en el contexto de una dinámica política que daba por sentado el carácter hegemónico de los distintos grupos oligárquicos.

Frente a esto, el procurador pechero sostenía la defensa de "sus" intereses por lo que el orden de importancia en el que estos aparecían expresados en el reclamo hecho a los regidores, es significativo. Lo que aparece como primer punto del Memorial es la solicitud del sexmero de poder "entrar al concejo"18 que equivalía a plantear que fuera reconocida formalmente la representación política que ejercía y con ello que también fueran reconocidos como actores políticos válidos. Sin embargo, la puja política entre elites pecheras y grupos oligárquicos tenía lugar en un espacio sociopolítico en el que emergentes grupos sociales intermedios (escuderos o caballeros de alarde, por caso) se fortalecían al convertirse en una actor político necesario y alternativo en el articulado de alianzas políticas. Esto imprimía una dinámica móvil a un contexto de aparente inmovilidad política al crear nuevos márgenes de acción.

Frente a este tipo de reclamos articulados coherentemente por los pecheros, los regidores solo podían intentar neutralizarlos recurriendo a agravios personales y alegando que las prerrogativas políticas que detentaban eran un atributo natural que se derivaba del estamento al que pertenecían ya que por gracia divina los cargos que el dispositivo político concejil contemplaba, se consustanciaban con la existencia de las oligarquías urbanas ${ }^{19}$

“E quanto toca a las amenazas non se fallará tal cosa nin que por nosotros la dicha cibdad e su tierra sea fatigada, antes por la gracia de Dios la regimos bien en quanto

${ }^{17}$ Memorial, docs. $\mathrm{n}^{\mathrm{o}}$ I y II, p. 276. El subrayado es nuestro.

18 “...que vosotros, señores, non consentides a mí, ni al que es sesmero de la dicha Cibdat Rodrigo, entrar en concejo, salvo quando a vosotros vos plaze. E dizides que non tien voz para fablar en concejo et que está allí por testigo e non en otra manera", Memorial, doc. I, p. 275

${ }^{19}$ A mediados del siglo XV, el contexto cronológico en el que nos estamos situando, los dos bandos linajes hegemónicos de Ciudad Rodrigo son los Pacheco y los Garçilópez. 
nuestro entender basta...los oficios mayores e menores de la dicha cibdat pertenescen a los linajes della, asy por privilegios conmo por antigua e ynmemorial costumbre..." 20

A partir de las denuncias presentadas por el representante pechero, se puede inferir la vertebración de un discurso político que consideraba a la organización política del reino como producto de un orden tradicional que debía responder en primer lugar a la defensa del bien común. Es por lo cual no intentaban disputar el control del aparato político local a las oligarquías ya que la materialidad del feudalismo castellano se manifestaba lógicamente en la vertebración de diferentes marcos ideológicos-mentales en cada uno de los sectores socioculturales y económicos existentes en el espacio concejil tardomedieval. Corresponde precisar los límites de las aspiraciones políticas pecheras: por un lado, el carácter excluyente del entramado institucional a nivel de la participación política de los sectores no hegemónicos; por otro lado, los condicionantes materiales que hacían a la reproducción del sector y que no permitían una contestación abierta del sistema político en su conjunto que, sin embargo, no impedía que se desarrollasen aspiraciones individuales: sobre todo a partir de la emergencia de tributarios enriquecidos que se hacían con los oficios pecheros, como el cargo de procurador. En 1455 es evidente que estos actuaban en el mapa político desde el lugar del privilegio no detentado desde el que podían hacerse escuchar, como se observa en la cita que sigue:

"lo otro que por culpa de vosotros e de vuestro regimiento están todas las puentes aderredor de la cibdat, que solían estar fechas, caydas por lo qual algunas vezes cesan de venir los mantenimientos e provesyones a la cibdat"21 (subrayamos el tono imperativo con el que se hace la denuncia)

El reclamo que hizo el procurador pechero trasluce su manejo retórico de un perfil "ideal" al que deberían responder las actuaciones de los oficiales concejiles y por ende, las diferentes instancias de representación y participación política, tanto de las oligarquías como del colectivo pechero. Así, denuncia por ejemplo que no hubiera instituciones ni personas que tuvieran la potestad legada necesaria como para someter a evaluación y/o coerción el amplio margen de acción individual y colectiva con el que las oligarquías urbanas desempeñaban las regidurías. Resaltaban que si el cargo recayera en algún vecino del común, éste cuidaría de actuar en el espacio político y público como "representante", atendiendo en consecuencia a comprometerse para responder al criterio de representación que en él habían depositado sus pares ${ }^{22}$.

Se enfatizaba desde el discurso político utilizado por el procurador pechero el carácter genuino de su representación y por ende la revocabilidad y no patrimonialización del ejercicio de los oficios en oposición al carácter cerrado de la participación política propia de los linajes, que según su apreciación convertían al poder político en una "propiedad" delegada del poder superior. Es evidente que los términos de la ecuación discursiva de los tributarios se pueden sintetizar en el siguiente esque-

${ }^{20}$ Memorial, p. 277.

${ }^{21}$ Memorial, p. 279.

22 "...Por ser regidores e omes poderosos non ha quien vos pueda apremiar para que dedes cuenta, la qual cuenta es entre vosotros conmo compañeros. De lo cual, sy el cargo diésedes a otro vezino de la cibdat, sería obediente e faría mandado cada ge lo mandasen...", Memorial, doc. I, p. 280. 
ma: los pecheros desarrollaron un ejercicio de la representación política ascendente, mientras que las oligarquías plantearon un esquema descendente.

En el mismo sentido, aparece trazado en el discurso que los pecheros utilizan que eran conscientes de ser los agentes que, por medio de la extracción de su surplus por parte de los sectores dominantes, garantizaban buena parte de la reproducción del entramado social. Si bien no hacían un cuestionamiento de base en lo que hacía a la naturaleza y dinámica intrínseca del sistema monárquico y sus despliegues en lógicas locales de poder, se permitían por el momento oponer ciertos reclamos tendientes a la defensa aparente de lo colectivo frente a los intentos predadores de las oligarquías villanas, materializados por ejemplo en las usurpaciones de los bienes comunales ${ }^{23}$ o las desigualdades que implicaba el abastecimiento de alimentos en los realengos castellanos $^{24}$.

Esto que acabamos de señalar es un fenómeno constitutivo del discurso político de pecheros mirobrigenses en el feudalismo tardío que se completó con una imagen ideal de la monarquía en general y del rey en particular, que les permitía presentar a los sectores hegemónicos como los "otros", los que se oponían al bien común de forma directa ya que de forma recurrente "ofendían" al monarca, dando sentido a un "nosotros" pechero que debía ser proyectado en el espacio de la constitución de ideales y discursos políticos como el defensor del buen gobierno del rey. Asumían los términos dicotómicos en que los grupos dominantes planteaban la visión del mundo: el juego de opuestos privilegiados/no privilegiados, pero modificaban su contenido sin cuestionar de fondo la naturaleza del esquema social dual. De aquí se desprende que los no privilegiados fueran los que defendieran la lógica inherente al articulado de poder enlazándose convenientemente con el afán de consolidación (bastante oscilante en la formulación táctica al menos) de la Corona.

Monsalvo Antón sostiene que en lugar de apoyarse en diferenciaciones socioeconómicas, la forma en que se ordenaban y defendían los intereses de los pecheros tenía por sustento una diferenciación topográfica de base: la experiencia de la vida cotidiana en espacios de villa o Tierra ${ }^{25}$ que en esencia, condicionaba los "tipos de violencias" que se desplegaban sobre las poblaciones del común en ellos asentadas, y que eran producto necesario de la morfología del régimen de aprovechamientos, que a fines de la Edad Media era básicamente inseguro en tanto fluctuaba entre una tradición de propiedades privilegiadas (típicas de su sector) y otra a la que también ellos podían acceder de usufructo colectivo ${ }^{26}$.

Si bien es válido en primera instancia este argumento, se puede señalar que al análisis de los resultados políticos de esta divisoria espacial, hay que hay que sumar

${ }^{23} \mathrm{Al}$ respecto LuCHIA, C: "Los pleitos por los términos comunales en el concejo de Ciudad Rodrigo en la Baja Edad Media", Historia, Instituciones, Documentos, nº 35, 2008.

24 “....syn ser el sesmero desta cibdat presente, pues está puesto en nombre de los pecheros que han de pagar los pechos e gastos que son convenientes a pro de la cibdat (...) e sy algo queredes dar gracioso, deve de ser de los maravedís de vuestros salarios et non de los agenos. De lo qual son mucho agraviados todos los pecheros, ansy los de la cibdat conmo de la tierra", Memorial, doc. I, p. 282.

${ }^{25}$ Monsalvo Antón, J. M: “Aspectos de las culturas políticas...”, op. cit., p. 265.

${ }^{26}$ Se trataba de dos tradiciones agropastoriles "legítimas pero antagónicas (...) eran funcionales para las economías de los caballeros pero inestables en su concurrencia", en Monsalvo AnTón, J. M: "Aspectos de las culturas políticas...", op. cit., p. 254. 
la incidencia del proceso de diferenciación social que atravesó al campesinado en general y al castellano en particular, a partir del siglo XIV, aunque la propuesta exceda los límites del trabajo.

En abril de 1456, cinco meses después de haber sido presentadas las denuncias de agravios por parte de los pecheros, el Corregidor Diego del Águila hizo llegar al concejo de villa el arbitrio de su voluntad.

Por cada una de las diecinueve reclamas que hicieron los procuradores pecheros, el Corregidor planteó la sentencia de su juicio, que podríamos agrupar en cuatro tipos generales para facilitar el recorrido analítico del problema: a) los denuncias sobre las que no podía expedirse y por tanto argumenta que necesitaba más tiempo para dar sentencia; b) resoluciones a favor de las oligarquías villanas; c) resoluciones a favor de pecheros y finalmente d) resoluciones que en lo aparente simulaban la neutralidad del funcionario regio pero que en lo esencial revelaban estrategias burocráticas para dar al sector pechero las ventajas necesarias que les permitiera conquistar la defensa final de sus intereses.

Dentro del primer grupo se encuentra manifestado el problema de fondo de la representación política en el feudalismo tardío y en particular en concejos de realengo: ¿a quiénes representaban los cargos disponibles en el entramado político?, ¿quiénes estaban excluidos de los mismos? ¿Cuál era la razón última de esa exclusión? ¿Estas cuestiones propiciaban cuestionamientos de base de los que tenían negado el acceso a los mismos?

“... Et vosotros, con el mando del regimiento avedes tenido e tenedes apropiados a vosotros todos quantos oficios avedes en esta cibdat e todos los repartides entre vosotros los regidores..." 27

No es de extrañar que ante este tipo de reclamos hechos por los pecheros, el Corregidor no tuviera que decir más que necesitaba tiempo para deliberar lo que fuera justo ya que era evidente que la denuncia encerraba un problema que excedía ampliamente la capacidad concreta del funcionario.

Dentro del segundo tipo, sólo encontramos una definición a favor de los regidores que habían alegado "época de carestía" frente a la denuncia pechera sobre el acaparamiento que hacían de la venta del pan:

"Quanto al décimo capítolo, parésceme que en esto es buena la respuesta dada por los regidores ${ }^{28}$..." sin embargo, acto seguido aclaraba: "Pero, sy el sesmero o escuderos dieren alguna razón más just, mostrándomela, yo lo veré e faré guardar ${ }^{\prime 29}$ con lo cual, quedaba invalidado el carácter concordante con la voz de los regidores que en principio parecía haber tenido el juicio del corregidor.

En el tercer tipo encontramos once denuncias de pecheros con dictamen favorable del Corregidor. La sola mención del número explicita la estrategia del funcionario

${ }^{27}$ Memorial, doc. I, p. 277.

28 "dezimos que sabe bien el dicho sesmero, o lo deve saber, que quando ocurrió carestía, asy se fizo e guardó, pero agor, por la gracia de Dios, pues que la sazón es buena e vale el pan a buen (ileg), sería agraviar a muchos de costas e non aprovechar en cosa (alguna) a la dicha cibdat", Memorial, doc. III, p. 283.

${ }^{29}$ Memorial, doc. III, p. 294. 
monárquico a favor de los tributarios y en desmedro de las oligarquías locales. Las razones de esta mecánica se vinculaban básicamente a la forma en que se ponderaban desde el poder central las complejas manifestaciones de lo político y de lo económico, sobre todo a partir del advenimiento de los Trastámara y el subsiguiente proceso de centralización estatal que implicaba entre otras cuestiones, que la monarquía interviniera en función de preservar su base social sin poner en juego el disfrute que las oligarquías tenían de sus prebendas políticas ${ }^{30}$.

Dentro del conjunto, nos interesa resaltar la denuncia del cobro desmedido de rentas y el acceso unilateral a su arrendamiento que presentaron los pecheros, con clara conciencia de que con estas prácticas se estaba atacando al sector social que garantizaba en lo esencial la reproducción del entramado social, por lo que el ataque se doblaba en ataque a la naturaleza del sistema monárquico.

“... señores, vosotros soys los fazedores e arrendadores de las rentas de concejo, con las quales rentas se fazen muchos agravios e daños a los vecinos de la cibdat e de su tierra, levándole el doblo (...) e quando menos liévanle trigo por cevada, que es el tercio demás de lo que deven pagar. E por ser la renta en poder del regidor o regidores e, aunque se quexan, todos callades e la justicia se tercia conmo le plaze. De lo qual es deservicio del señor rey e despoblamiento de su tierra"31 (el subrayado en negritas es nuestro).

La respuesta del Corregidor es indicativa de la presión que los grupos de tributarios enriquecidos ejercían ${ }^{32}$ para poder acceder a algunas de las prerrogativas políticas y económicas que el sistema concejil ponía a disposición de los sectores hegemónicos como el arrendamiento de rentas ${ }^{33}$ :

${ }^{30}$ La necesidad de no afectar la base impositiva sobre la que descansaba la centralización de las estructuras monárquicas, que materializaban los tributarios, fue uno de los principales condicionantes para que el fenómeno adquiriera un perfil original. De hecho, el siglo XV se caracteriza en lo político por ser un tiempo en el que las oligarquías urbanas por definición se enfrentaban al monarca en tanto que los pecheros acudían a su defensa. A esto se debe que el advenimiento del reinado de Isabel I generó grandes expectativas en los pecheros que confiaban en una reivindicación de las humillaciones sufridas desde la conformación del estamento en el siglo XIII a instancias de la caballería villana.

En lo económico, los tributarios se definían por el lugar que ocupaban en el los múltiples derechos de uso que el marco jurídico-ideológico propio del feudalismo castellano se encargaba de regular. Se trataba de un complejo tablero de ajedrez en el que la monarquía trataba de garantizar la satisfacción de los múltiples intereses que atravesaban a tributarios de los concejos de villa y sus respectivas Tierras, lo que a la vez garantizaban la existencia de los sectores hegemónicos, que lideraban los planos locales y regionales formales de poder.

${ }^{31}$ Memorial, doc. I, p. 287.

${ }^{32}$ Sobre la incidencia de mecanismos de diferenciación social sobre distintas formaciones señoriales, y sus consecuencias a nivel de la morfología del sector pechero ver DA GRACA, L: "Notas sobre la diferenciación social en señoríos castellanos (abadengo y realengo, ss. XIV - XVI), Studia Histórica, Historia medieval, 17, 1999,

${ }^{33}$ Una originalidad del área de concejos es que el poder señorial no interviene en el arrendamiento de rentas: "Las disposiciones relativas a quiénes están facultados para la tarea aluden al campesino rico y prohíben que participen de ella la justicia y regidores de la villa (...) de todos modos la documentación sugiere que es el sector de pecheros el que predomina, al amparo de relaciones de tipo clientelar con los regidores", en Da Graca, L: Poder político y dinámica feudal. Procesos de diferenciación social en diferentes formas señoriales, siglos XIV-XVI, op. cit., p. 154. 


\begin{abstract}
“... que ningund regidor arriende rentas de concejo, salvo las yunterías e devasos e piélagos de la puente (...) que se sacaron avido acatamiento, que conmo sean rentas las que mas valen para provecho de la dicha cibdat e su tierra, que a fin de las acrecentar que non se abaxen que se dé logar a que todos las puedan arrendar (...) o mando al bachiller Sancho García, mi alcalde, que al tiempo que sean juntos la primera vez los sesmeros de la dicha cibdat e de su tierra, que lo platiquen con ellos e, avida plática e información dellos, sy acordaren que es bien que todavía se defienda que todavía non arrienden las dichas rentas ecebtadas los regidores" ${ }^{\prime 34}$
\end{abstract}

Al respecto la denuncia final del Memorial reviste una importancia interpretativa singular: en ella el sexmero denuncia procesos de apropiación individual de bienes públicos ${ }^{35}$ como plazas y calles, a sabiendas de que no fueron otorgadas licencias reales a los sectores oligárquicos para que así se haga. Aunque los regidores alegaron no haber ofendido lo "público", habiendo en todo caso intercambiado un bien por otro de mayor beneficio para el conjunto, se cuidaron de solicitar en la réplica que presentaron tanto la firma del escribano como el testimonio de la prueba presentada.

Pero lo significativo es la sentencia que fue dada por el Corregidor:

“... mando que todas las calles e placas que se han dado desde veynte años a esta parte que se quiten a los que se dieron e se buelvan a la cibdat. E cualquier cosa en ellas edificado que sea destruydo e reducido al primero estado" ${ }^{36}$ (el subrayado es nuestro)

Esta posibilidad de destruir las edificaciones hechas en términos usurpados, abría puertas de difícil retorno (aunque solo se tratara de un recurso estratégico del funcionario y no de una medida que fuera a concretarse). La defensa de los bienes comunes que pecheros y monarquía enfrentaban discursivamente a los intereses sectoriales de las oligarquías puso en evidencia la convivencia de dos identidades y/o lógicas políticas enfrentadas: la que aparece reflejada en la retórica deiscursiva del Memorial que contemplaba la esfera de lo monárquico como intrínsecamente asociada a lo popular y a lo colectivo y enfrente, la oligárquica, que sólo recurría al peso de los privilegios basados en la estabilidad del estamento. En este sentido, la defensa de la tradición que las oligarquías hacían impliocaba una lógica de signo antiguo que retrasaba y mucho, en el nuevo juego de poder que se había abierto en el medio concejil castellano con los Trastámara. Los sectores hegemónicos tradicionales no habían sido capaces de captar, entre otras cosas, lo que en términos políticos implicaba la emergencia de nuevos grupos de poder (como las élites pecheras) que empezaban a demandar un lugar legítimo en el gobierno concejil. Finalmente, el cuarto tipo reconfirma las estrategias diagonales que hacía el Corregidor para poder beneficiar a la postre a las elites pecheras. La imparcialidad del funcionario monárquico no se explicitaba por el manejo formal que hacía él también de la retórica política discursiva que estaba

34 Memorial, doc. III, p. 295.

35 Es interesante la noción que los tributarios tenían del bien público: "son públicas del señor rey e para bien e uso de los vezinos della, las quales non pueden (ser) enegenadasnin ocupadas por ninguna persona syn licencia del dicho señor rey”, Memorial, doc. I, p. 290.

${ }^{36}$ Memorial, doc. III, p. 296. 
disponible en un período de emergencia de nuevos grupos de poder que no aparecían contemplados en ella:

“...mando que vaya un regidor e el sesmero de la cibdat con mi alcalde a ver las dichas pontezillas (...) e se reparta para ello lo necesario entre los que han de contribuyr en adobo de puentes, segund de derecho, e non solamente los pecheros" ${ }^{\$ 37}$

\section{EL DECLIVE DE LO QUE FUE: LA CRECIENTE DEBILIDAD DE LA PARTICIPACIÓN POLÍTICA COLECTIVA DE PECHEROS MIROBRIGEN- SES EN LA SEGUNDA MITAD DEL SIGLO XV}

Como hemos dicho, de acuerdo a las particularidades geopolíticas ya señaladas de este concejo, desde fines del siglo XIV los vecinos mirobrigenses se beneficiaron de importantes ventajas y privilegios que contribuyeron a consolidar una elite de pecheros enriquecidos que lograron una actuación política sólida y sostenida en el tiempo.

En noviembre de 1382, Juan I eximió a Ciudad Rodrigo y su Tierra del pago de trescientas cáñamas de las monedas y del pago de martiniegas, alfolí de sal y yantares por el plazo de diez años con lo que seguramente se aceleró y radicalizó este proceso de acumulación y enriquecimiento de un sector del "común" que ya venía desplegándose ${ }^{38}$.

"Nos el rey, por fazer bien e merçed al conçeio e vecinos e moradores de la çbdat de Çibdat Rrodrigo e de su término, por muchos males e dannos e destruymientos que reçibieron de las nuestras gentes que conusco fueron en las dos entradas que nos fezimos en Portugal por la dicha çibdat (...) fasta diez annos primeros siguientes conplidos sean quitadas a la dich çibdat e a su término cada anno trezientas cánamas de monedas, que las non paguen; e otrosí que en estos dichos diez annos que la dicha cibdat e los vecinos della e de su término que non paguen martiniega nin alfolí de sal, segund lo solían pagar fasta agora de la sal que solían traer de Portugal, et otrosí de yantar, salvo sy nos fuéremos en la dicha çibdat por nuestro cuerpo"39

Insistimos en sostener que este tipo de beneficios derivados de la situación topográfica y geopolítica de Ciudad Rodrigo deben de haber redundado en el despliegue de un sector enriquecido del estamento pechero con características disímiles respecto de sus pares de otros $\operatorname{concejos}^{40}$, que les permitió entre otras cosas, apropiarse a lo

37 Memorial, doc. III, p. 293.

38 El proceso de diferenciación social del campesinado en Europa Occidental en el siglo XIV es ampliamente conocido y encuentra las bases de su estudio en DoBB, M: Estudios sobre el desarrollo del capitalismo, México, 1971 (la primera versión es de 1946). Para el caso hispano, DA GrACA, L: Poder político y dinámica feudal. Procesos de diferenciación social en distintas formas señoriales (siglos XIV - XVI), Valladolid, 2009.

39 Barrios Garcia, A; Monsalvo Antón, J. M; Del Ser Quijano, G: Documentación Medieval del Archivo Municipal de Ciudad Rodrigo, Salamanca, 1988 (en adelante: IDEM), Doc. n 23, p. 56. El privilegio se reconfirma en los años 1379, 1387, 1398, 1406 y 1407, respectivamente..

${ }^{40}$ En 1399, los pecheros enriquecidos de la Tierra lograron que Enrique III les prorrogara por dos años la exención del pago de monedas: "sepades que vi una petición que me enbiastes, por la qual me fiziestes saber en conmo el rrey don Johán, mi sennor e mi padre, que Dios perdone, considerando los muchos males e danpnos que esa çiudat e su tierra avie resçebido e rrescibie de cada dí, vos fizo merçet 
largo de la primera mitad del siglo XV de la representación política del total de los no privilegiados, solo para conseguir beneficiarse en términos personales y privados del usufructo discursivo de la representación del sector y sobre todo, de la condición de subyugados que la mayoría evidenciaba ${ }^{41}$.

Este proceso se debe de haber fortalecido con las numerosas usurpaciones de comunales ${ }^{42}$ que la documentación refleja, ya que al ocupar las tierras realengas y abortar con ello los usos comunitarios de las mismas, las oligarquías básicamente profundizaron el proceso de diferenciación interna de las comunidades campesinas del que a su vez se beneficiaron con la obtención de trabajadores asalariados ${ }^{43}$.

Esto permite delinear los perfiles de la elite pechera mirobrigense que se manifiesta, por ejemplo, en la defensa paradójica del pretendido carácter lícito de algunas usurpaciones de comunales que ellos mismos habían hecho. Al respecto, es ilustrativo el caso de Juan Ferrández Arnedo, un pechero enriquecido que en diciembre de 1398 apeló la sentencia del alcalde que lo impelía a devolver la tierra de la que se había apropiado y que al evidenciar conocimiento de los procedimientos legales, rebate la taxonomía que equipara a un no privilegiado con alguien que ignoraba los procedimientos jurídico-legales del medio en el que se desarrollaba:

e quitó a essa çiudat todos los sus pechos e derechos e monedas, (...) salvo las alcabalas", IDEM, doc. $\mathrm{n}^{\mathrm{o}} 46, \mathrm{p} .89$.

${ }^{41}$ Como ejemplo de lo que comentamos, citamos el siguiente caso: en marzo de 1413 la monarquía aceptó no modificar para Ciudad Rodrigo la cuantía mayor de pecheros que era de 4000 maravedíes ya que los campesinos más ricos se oponían al establecimiento de una nueva cuota: "sepades que vi vuestra petiçión en que me enbiastes dezir que los mis pecheros vecinos desa çibdat e su tierra eran muy agraqviados los pobles con los rricos, asi en los pechos que a mi han de pagar conmo en los conçejales (...) que los pecheros más abonados non querían consentir en ello (...) sobre lo qual avía entre vosotros debates e contiendas ..." IDEM, doc. $\mathrm{n}^{\circ}$ 67, p. 112.

42 A juzgar por la documentación concejil, las usurpaciones de comunales deben de haber comportado una tendencia marcada en Ciudad Rodrigo. Como consecuencia de las Cortes de 1432 y 1433 en las que se trató la forma de llevar a cabo la restitución de términos concejiles, en 1434 aparecen luego de 13 interrogatorios a pecheros, inicia una larga lista de emplazamientos a pecheros enriquecidos y sectores de la oligarquía local para que devuelvan al usufructo colectivo concejil los términos que habían sido ilegalmente ocupados, en Barrios Garcia, A; Monsalvo Antón, J. M; Del Ser Quijano, G: Documentación medieval del archivo municipal de Ciudad Rodrigo, Salamanca, 1988, docs. ${ }^{\circ} 162$ a $\mathrm{n}^{\mathrm{o}} 255$, pp. 238-294.

${ }^{43}$ Carlos Astarita ha argumentado que al desplegarse nuevas formas económicas sobre los concejos realengos y de particulares en el periodo tardomedieval destinadas a la producción de valores de cambio, esencialmente en el espacio físico de la Tierra, sectores enriquecidos del campesinado rural se habrían convertido en acumuladores capitalistas lo que se trasladaba a la búsqueda de mecanismos que les permitieran diferenciarse como clase con sus propios objetivos programáticos no tradicionales para poder así adquirir un perfil social acabado que los habilitase para plasmar en lo político su preeminencia económica. Lejos de impedir su conceptualización como clase, para el autor los pecheros castellanos conformaron una clase cuya característica básica en el feudalismo tardío fue su profunda estratificación. Esta estratificación del sector es precisamente la que sostiene para él la ambigüedad del papel sociopolítico de las elites pecheras: en tanto vecinos de la comunidad, arrendaban el cobro de rentas y empleaban mano de obra asalariada, al tiempo que desde sus filas salían los procuradores pecheros, que se entendía, portaban sus cargos en representación de los intereses de los demás pecheros. Para Astarita, es claro el papel que cumplieron como agentes funcionales a la reproducción de los sectores dominantes, en tanto entiende que su actuación política estaba encaminada en última instancia a aplacar el conflicto social; Astarita, C: "Procuradores pecheros", Del feudalismo al capitalismo. Cambio social y político en Castilla y Europa Occidental, 1250-15200, op. cit. 
"Et el dicho Juan Ferrández dixo que sentiende ser por agraviado de la dicha sentencia quel dicho Pero Guillén, alcalle, contra él dava; que apellava para ante Vasco Alffonso, alcalle de las alçadas, et que pedía al dicho alcalle que gela otorgase et le asignase prazo a que se apresentase contra ella antél" 44

La capacidad de gestionar los términos de un concejo de frontera que tuvieron los pecheros, mientras la nobleza y la caballería local se encontraban inmersas en el proceso belicoso, seguramente ayudó a que los labradores enriquecidos de la Tierra mirobrigense, por encontrarse fuera del alcance efectivo de los dispositivos de control del concejo cabecera, tuvieran que desarrollar una actitud política y discursiva de defensa a rajatabla de lo público y propio del concejo (como mecanismo de protección frente a la rapiña voraz que el conflicto lógicamente importaba). Así, es posible también que hayan sido capaces de vertebrar una capacidad de intervención política que se caracterizaba por el recurso a la retórica formal en beneficio de ellos en particular que puede ser percibida en situaciones en las que llegaban a desafiar a los poderosos locales y al poder central, por ejemplo, arrogándose la autodeterminación del no pago de portazgos en días de feria:

"ordenaron e mandaron (...) que ninguno non pague porazgo nin portadguillo el tienpo e días de la feria desta çibdad, porque diz que non se acostunbra pagar. E fue en esta ordenança un alcalde con los regidores, e pregonóse; e el corregidor e otro alcalde dixeron que non heran en ello" 45

Otro ejemplo, podemos encontrarlo cuando el mismo Juan II amenazó a los vecinos de Ciudad Rodrigo con tener que comparecer ante el rey en persona en las Cortes o con la privación de ejercer los oficios, debido a la recurrente negativa de los pecheros de obedecer la autoridad real respecto de la venta de vino de la Tierra en su término ${ }^{46}$. Hay que resaltar la evidencia de agresión física que se registraba en contra de los funcionarios reales y de los de la justicia concejil ya que el rey trata con especial atención la salvaguarda física de los mismos ${ }^{47}$ :

“...otrosý, vos mando que non firades nin matedes nin lisiedes al dicho Juan de Salas, mi portero, nin a los procuradores e personas que con él fueran a vos levar e notificar las dichas mis cartas, ca yo por esta mi carta tomo al dicho mi portero e a los que con él fueren en mi seguro e anparo e defendimiento"48

${ }^{44}$ IDEM, Doc. $\mathrm{n}^{\mathrm{o}} 85, \mathrm{p} .85$.

${ }^{45}$ IDEM, doc. $n^{\mathrm{o}} 112$, p. 189.

46 “... que parezcades e parezcan ante mó en la mi corte presonalmente, del día que vos enplazare a quinze días primeros seguientes, so la dicha pena e de privación de los ofiçios, a qualquier escribano público, que para esto fuere llamado, que dé ende al dicho mi portero testimonio signado con su signo, por que yo sepa en conmo conplides e cunplen mi mandato", IDEM, doc. n $^{\circ} 134$, p. 215. Aun en 1428, el rey sigue solicitando al concejo que cumpla con su sentencia, por lo que le impone una multa de 2000 maravedíes.

${ }^{47}$ Este tipo de evidencia es el que permite sostener que la no violencia pretendida como un calificativo del sector que sostienen autores como Monsalvo, no es más que un recurso retórico de los procuradores pecheros.

${ }^{48}$ IDEM, doc. $n^{\circ} 134$, p. 215. 
Hacia mediados del siglo XV, la imagen del rey como justiciero capaz de recomponer una situación de "mengua de justicia" expresa no tanto una sólida convicción por parte de los dominados, sino una estrategia discursiva que obligaba al monarca a aplicar y hacer valer su autonomía relativa frente a las fuerzas dominantes del reino. Sin embargo, esta imagen no respondía a una creencia ingenua de los pecheros sobre las capacidades salomónicas de su rey, sino que era producto de un uso estratégico y táctico de esta imagen idealizada de la naturaleza real por parte de los procuradores de las aldeas para presionar al rey y lograr así que se inclinara en favor de los sectores rurales. Lo que se buscaba era que la voluntad real terminara por beneficiar a los labradores enriquecidos que ubicándose en el lugar discursivo de los que carecían de privilegios, lograban un acceso estratégico a los comunales, por ejemplo, al proveerse de mano de obra asalariada para poner en producción tierras fiscales y beneficiarse con pingües ganancias de esta doble condición de campesinos que, con criterios que no eran los del sector, contrataban a otros campesinos empobrecidos para poner en producción tierras que previamente habían acaparado.

Se trataba en definitiva, de la apropiación que hacían unos pocos en nombre de todos, de la imagen propagandística del monarca como rey soberano y justiciero que estaba por encima del entramado de conflictos sociales, y que es típica del período trastámara en general y del reinado de los Reyes Católicos en particular. Sin embargo, es en este punto en el que la actuación ambivalente de la monarquia queda al descubierto, ya que no siempre el fallo favoreció a los campesinos ${ }^{49}$ sino que en su juego de poder estratégico, tuvo que favorecer a algunos sectores de las oligarquías villanas para poder sostenerse en el tiempo y no atentar de base contra el orden socioeconómico y político establecido. En el caso de Ciudad Rodrigo, la corona parece favorecer al linaje de los Garçilopez en desmedro de los Pacheco a lo largo del siglo XIV, al menos en lo que se puede inferir a partir de las resoluciones judiciales ${ }^{50}$.

En junio de 1421 y haciendo un uso evidente y estratégico de la retórica formal del discurso político privilegiados/no privilegiados, los vecinos de Fuenteguinaldo (un concejo de Tierra que había sido segregado a favor de Garçi Ferrández) solicitaron e imploraron al Concejo cabecera de Ciudad Rodrigo que no les quitase la dehesa que, en su antigua condición de vecinos de la Tierra, habían usufructuado:

“...el conçejo e alcalles e omes buenos de Fuenteguinaldo nos encomendamos en la vuestra merçed, conmo a nobres (sic) señores a los quales somos tenudos a todo vuestro servicio e mandado. En rrazón de lo que aý tratastes con los buenos onbres que a ella enbió el conçejo, señores, plegamos por merçed de non nos querer fazer

\footnotetext{
${ }^{49}$ Sólo por citar algún ejemplo, en mayo de 1437, se libra una ordenanza en la que se obliga a los labradores a pagar pechos reales y concejiles en moneda, so pena de 600 maravedíes de multa, IDEM, doc. $\mathrm{n}^{\mathrm{o}} 267$, p. 305 .

${ }^{50}$ Como se ha señalado, 1434 aparece como un año clave en el tratamiento jurídico, concejil y monárquico, de los conflictos por los comunales. En ello, se puede observar los usos tácticos de la monarquía para lograr beneficiar al linaje de los Garçilópez, amedrentando el patrimonio de los Pacheco. Así, por ejemplo, 3 de mayo de ese año se emite sentencia favorable al carácter comunal de Pelapulgar que había sido apropiado por Diego Alfonso Pacheco, impidiéndole a este que presente otros testigos, IDEM, doc. $\mathrm{n}^{\circ} 188$, p. 251.
} 
desaguisado e de nos querer dexar nuestra defesa, segunt que bevieron vuestros padres e vuestros avuelos, e de nos fazer buena veçindat..."51

Asumimos que se trata de la evidencia de la fortaleza política de los pecheros enriquecidos de antigua tierra concejil ahora convertida en señorío de particulares ya que en 1428, el concejo de la ciudad emite una ordenanza permitiendo a los pecheros de villa y tierra capturar el ganado de los de los términos segregados que anden pastando en sus términos, alegando que éstos lo habían instaurado como costumbre previamente $^{52}$, con lo que se confirmaría la preminencia política de estos pecheros, potenciada por el fenómeno de los términos segregados, ya que es evidente la impunidad con la que parecen actuar. Se trata de pecheros de pequeños señoríos de particulares que parecen tener mayor libertad de acción y de defensa de sus intereses que aquellos otros, que necesitaban ampararse en el andamiaje político administrativo del concejo villano, en lo que seguramente es una evidencia de que actuaban como clientela política de las oligarquías en lugar de haber podido instalar una cultura política propia y del sector, como sí podían hacerlo los habitantes de la Tierra, tanto de la que había pasado a conformar los señoríos de particulares como la que permanecía en poder del concejo de Ciudad Rodrigo. Veamos otro caso que fundamenta esta idea:

En 1419 vecinos de El Saúgo arrogándose su autorepresentación y la del concejo rural al que pertenecían, denunciaron la usurpación de devesas de los lugares de Robledo y Robleda. Lo que en apariencia no era más que más que la fórmula conocida en la que solía expresarse la voz de los pecheros en realidad dejaba ver las fracturas socioeconómicas del sector básicamente en la forma en que esto se plasmaba a nivel de lo político y sobre todo, del discurso político. A principios del siglo XV, la lucha facciosa entre elites pecheras reflejaba los resultados del proceso de diferenciación social y económica del sector lo que también era evidente en la retórica formal de los procesos judiciales. En el caso que citamos, en tanto que unos utilizaban y se beneficiaban de la patrimonialización de los términos comunales, otros, respondiendo a una lógica campesina más tradicional (al menos en que apelaban discursivamente a lo colectivo) solicitaron al juez que se respetase el carácter comunal del término de Robredo y se penalizara a los apropiadores, mayoritariamente campesinos enriquecidos, que obviamente no eran a su entender consecuentes con la lógica del sector ni respondían por tanto a la relación funcional entre los pecheros rurales y la existencia de los pastos comunes. Veamos como aparece en la documentación:

“...porque rreçebistes por testigos los vecinos de la dicha Rrobreda, a los quales en común e en singular venía al dicho tiempo e antes e agora provecho del vençimiento deste pleito, sy contra nos fuesse, e han avido a los dichos tienpos e antes e han agora provecho, en singular de los dichos derredores, e han seýdo e son partes en este dicho

${ }^{51}$ IDEM, doc. $\mathrm{n}^{\mathrm{o}} 98$, p. 176

52 "ordenaron e mandaron (...) por cuanto los vezinos e moradores de los señoríos guardan sus términos e prendan en ellos a los vezinos e moradores de la tierra desta çibdad e ellos comen los términos e devasos de la dicha çibdad e su tierra con sus ganados, mandaron que los vecinos e moradores que los prenden por ellos e les quiten sus ganados e los traygan a la dicha çibdad, para que fagan dellos lo que devieren con derecho", IDEM, doc. $\mathrm{n}^{\mathrm{o}}$ 141, p. 219. El pleito se resolvió en 1432, cuando los pecheros del concejo de Fuenteguinaldo consiguieron luego de una conciliación, llevar sus animales a pastar libremente allí, IDEM, doc. $n^{\circ} 156$, p. 228. 
pleito, e han pagado e contribuydo e pagan e contribuyen en él, quanto más que non fazen fee ninio prueba, pues no son publicados; e demás que por los testigos de fuera del dicho lugar se pruevan los dichos devasos" ${ }^{53}$

El discurso político por medio del cual se expresan los pecheros en 1419 es diferente al que utilizan en 1455, en ocasión de presentar ante el Corregidor las denuncias por agravios sufridos por la acción de los poderosos ${ }^{54}$.

Entre ambos memoriales puede observarse una diferencia sustantiva: en tanto el primero recoge las voces de los pecheros mirobrigenses sin "procesamiento previo" por lo que no se hacen intentos por simular un pretendido colectivismo del sector, en el segundo caso citado (el de 1455) y al menos en lo formal de la estructura de su retórica los procuradores pecheros hicieron sus denuncias basándose en una tradición, insistimos, en apariencia igualitaria para plasmar con mayor contundencia la defensa de los intereses a los que respondían y poder así dejar al descubierto la "mengua de justicia" que afectaba a la mayoría del sector, pero no por solidaridad con sus pares empobrecidos, sino con el objetivo final e inconfesado de beneficiar con esto a unos pocos: los que se habían enriquecido con el proceso de diferenciación socioeconómica del sector.

Así, es evidente que al promediar el siglo XV, los procuradores pecheros hacían unos usos tácticos de la retórica formal en la que se inscribía el discurso político general y del que los pecheros enriquecidos se apropiaban para conseguir prerrogativas económico, sociales y políticas, o mantener intactas las que para ese entonces se habían convertido en prebendas históricas de la elite del sector.

\section{CONCLUSIONES}

En tanto que en el memorial de 1419 no aparece ningún intento por distraer la atención de los oficiales concejiles de las disputas que atravesaban al sector, ya que solían aparecer las denuncias de los pecheros comunes en contra de otros enriquecidos; en 1455 el tono del memorial es el de un conjunto compacto que se posiciona como un todo abroquelado y coherente frente a los embates de los regidores y de las oligarquías villanos a las que pertenecían.

Lo que podría asumirse como falta de cohesión y debilidad estructural de la cultura política de pecheros mirobrigenses que parece haber favorecido el afianzamiento de los linajes señoriales urbanos, como generalmente aparece en estudios recientes ${ }^{55}$, tal vez en realidad esconda el resultado tangible de la dinámica histórica a través de la

${ }^{53}$ IDEM, doc. $\mathrm{n}^{\mathrm{o}}$ 89, p. 155.

${ }^{54}$ Las pesquisas llevadas a cabo por oficiales designados según la ocasión por el concejo o por la propia monarquía, la demarcación de términos y el recurso a testigos lugareños que contemplaban los dispositivos jurídicos eran un mecanismo de disciplinamiento social que se deja entrever en la retorica de los documentos. La solución de los pleitos estuvo inicialmente en manos de los jueces y regidores locales designados por los propios concejos, pero la presencia de miembros de las oligarquías concejiles entre los principales usurpadores obligó a habilitar otras instancias. El detalle en LuchiA, C: Tesis doctoral inédita, op. cit., Cap. IV: "Poder político y propiedad comunal".

${ }^{55}$ LuCHIA, C: Tesis inédita, op. cit., p. 222. 
cual se había fortalecido con contundencia la elite de pecheros de concejos rurales. Ellos habían sido capaces de subsumir a sus intereses el total del discurso político accesible en la Baja Edad Media. Se habían apropiado también de la defensa colectiva del estamento pero manteniendo intacta la capacidad de usufructuar la retorica formal que hacía hincapié en la desigualdad enunciada en términos de privilegiados no privilegiados, por medio de lo cual podían disimular la intención de mantener a rajatabla la defensa de sus intereses, abrigados en un enunciado colectivista, que sin embargo, lo que hacia era reforzar el beneficio privado y personal de algunos campesinos enriquecidos.

A esto se debe que el discurso político parece atenuarse entre un memorial y otro: la dinámica concreta del sector pechero entre 1419 y 1455 nos informa acerca de la manera en que la acumulación patrimonial de algunos campesinos se plasmaba en lo político: no era más que la forma en que estos hombres usaban y participaban de instancias políticas que estaban constreñidas a unos pocos canales de canalización en los tiempos del concejo cerrado y que sin embargo, era por donde podían inmiscuirse las prácticas políticas de los labradores enriquecidos de Ciudad Rodrigo, que lograban así hacer política sin estar en el poder.

La participación política del sector pechero mirobrigense tardomedieval tenía estas particularidades: unos pocos habían captado y condicionado la forma en que el colectivo se expresaba.

En este sentido, es claro que lo que se evidencia entre 1419 y 1455 no es el colectivo manifestándose políticamente, sino una minoría. A ello se debe la imagen de la participación política de los pecheros que es común encontrar en la documentación concejil propia de la segunda mitad del siglo XIV y que se fortalece a lo largo del siglo XV. Esta imagen hace hincapié en lo colectivo e igualitario, lo pacífico y representativo del sector aunque lejos de reflejar la realidad del proceso, es indicativa de lo opuesto: se exacerbaba en lo discursivo un comportamiento ideal del sector pechero, que lejos estaba de responder a un criterio de realidad.

La participación política de tributarios a mediados del sigo XV respondía a una fórmula novedosa de representación: un procurador que provenía de la elite pechera actuaba en nombre de un "nosotros" al que en realidad no representaba pero de cuya existencia se beneficiaba.

La conformación de una cultura política propia de pecheros mirobrigenses enriquecidos es contundente: no era sólo producto de formulaciones ideales, tenía base de sustentación en años de gestión de las lógicas productivas concretas que se configuraban en un contexto político particular, del que eran producto necesario. La posibilidad de revocarlas, modificarlas o renegociarlas comenzaba ahora a materializarse debido a la gradual y sostenida vertebración de este ideario político de pecheros enriquecidos autónomo y particular. 